\title{
Social Support and its Impact on Self- Sabotaging Behavior: A Case Study
}

\author{
Dion Robeau Thompson* \\ Department of Psychology, Bahamas \\ Received: 制: Octobet 29, 2018; Published: ㄴㅔㅛ: November 09, 2018 \\ *Corresponding author: Dion Robeau Thompson, Department of Psychology, Bahamas
}

\section{Introduction}

Some studies have reported there are potential benefits to having a social support system, which can indirectly offset extenuating self-sabotaging behaviours. This case study investigates the role of cultural expectations, and personal dispositional traits on reducing self-sabotaging behaviour. Rosenberg Self-Esteem Scale [1], was used for levels of self-esteem, with a series of interviews. They highlighted that there seem to be a link between limited cognitive awareness and self-sabotaging behaviour. Further studies are needed to understand to what extent this phenomenon can be applied to a larger population. Social relationships within a cultural paradigm appears to be one the key elements in maintaining a good mental health [2]. It seems to offer a match in the assistance need to offset some aspect of distressors, especially when linked with the individual temperament $[3,4]$.

Because persons have varying self-esteem levels, Bolger and Kessler [5], concluded that support might be more beneficial if it is experienced at a pre-conscious level. They termed as an "invisible support experience." As a consequence, the persons are more willing to explore alternatives to their distressors and are less reliant upon others to problem solve effectively their concerns. This idea is supported by Barrera (1986), who opined that active support required the persons' own full understanding what level of assistance were needed to reduce the internal impact, consequently, mitigating the external effect. As concerns may arise from a myriad of stressors, it is complex [6]. Thus, being able to reflect upon previous decisions, and actively learn how to manage emotions is essential to a healthy psychological orientation (Hoyle, 2010).

\section{Method}

The primary participant was a European female working as an Educator in Asia, possessed a positive rapport with her father, but experienced a difficult relationship with her mother. Within her work environment, she was unable to create a cordial and cooperative relations and found it hard to accept or accommodate work readjustment responsibilities. On the other hand, she could not tolerate when she was not accommodated for personal reasons. All 7 participants; 1 European female, 5 Asian females and 1 male African American participant completed a Rosenberg SelfEsteem Scale (RSE) [1], self-esteem inventory. These were done in conjunction with the Big Five personality Questionnaire, along with a series of interviews.

\section{Results}

On the RSE the primary participant received a score 12 out of 30 , which was below the range of 15 , indicating a low-selfesteem. Additionally, she was the only participant who scored high on neuroticism. Protective amnesia appeared to have occurred with regard to her responses, which involved her self-sabotaging process. On the other hand, she lucidly was able to systematic recall all occupational demands made of her. Throughout the interview process, only the primary participants were unable to make the transition between her responses and the outcome received in the relationship building process. Additionally, she was the unable to adequately approximate her own level cooperativeness, and/or likeability.

\section{Discussions}

The lack of intimate positive exposure might have placed the subject at a disadvantage in bonding, and thus, unable to adjust her desires, and understand to social cues given by her supervisors and co-workers (Prapavessis and Grove). Silva et al., highlighted that social communication, if not acquired early in life can often negatively impact miscommunications outcome later on in life. Berglas and Jones opined that understanding feedbacks was critical in preventing self-sabotaging acts. Horney [7] pointed out 
that when self-efficacy is threatened, the need for power overrides social acuity and reasoning. Acton [8], purported that expected negative interactions fuel behaviors towards self-defeating actions, and Budhananda [9] concluded that it lowers internal framework attributed needed to self-regulate feelings. These might help explain the primary participant's inability to prevent herself from engaging in self-sabotaging acts.

\section{Conclusion}

There is a propensity to self-sabotage when persons do not experience personal, and cultural social support, because they assist in framing perceptions of others action at large. When these experiences are match with the cultural expected paradigm to work from, a person can modify their expectations to meet the social demands because of practice. Without having opportunities to practice safely feelings, and learning intimate cues of engagement, person develop feelings of intolerance due to the loss of self-worth. This seems to push persons towards self-sabotaging, while trying to regain control over their environment. More research is need to examine the cross-cultural factors, which might be influence the process of the investigation.

\section{References}

1. Rosenberg M (1965) Society and adolescent self-image. Princeton: Princeton University press.

\section{ISSN: 2574-1241}

DOI: $10.26717 / B J S T R .2018 .10 .002021$

Dion Robeau Thompson. Biomed J Sci \& Tech Res

This work is licensed under Creative Commons Attribution 4.0 License

Submission Link: https://biomedres.us/submit-manuscript.php
2. Baumeister RF, Leary MR (1995) The need to belong: Desire for interpersonal attachments as a fundamental human motivation. Psychological Bulletin 117(3): 497-529.

3. Berkman LF (1995) The role of social relations in health promotion. Psychosomatic Med 57(3): 245-254.

4. Park J, Kitayama S, Karasawa M, Curhan K, Markus HR, et al. (2013) Clarifying the link between social support and health: Culture, stress and neuroticism matter. Journal of Health Psychol 18(2): 226-235.

5. Bolger N, Zuckerman A, Kessler RC (2000) Invisible support and adjustment to stress. Journal of Personality and Social Psychology 79(6): 953-961.

6. Shrout PE, Herman CM, Bolger N (2006) The costs and benefits of practical and emotional support on adjustment: A daily diary study of couples experiencing acute stress. Personal Relationships 13(1): 115134.

7. Horney K (1935) Conceptions and misconceptions of the analytical method. Journal of Nervous and Mental Disease 81: 399-410.

8. Acton SG (2003) Measurement of impulsivity in a hierarchical model of personality traits: Implications for Substance Use. Substance Use \& Misuse: Marcel Dekker Inc 38(1): 67-83.

9. Budhananda S (1990) Will power and its development. Prabuddha Bharata: Calcutta.

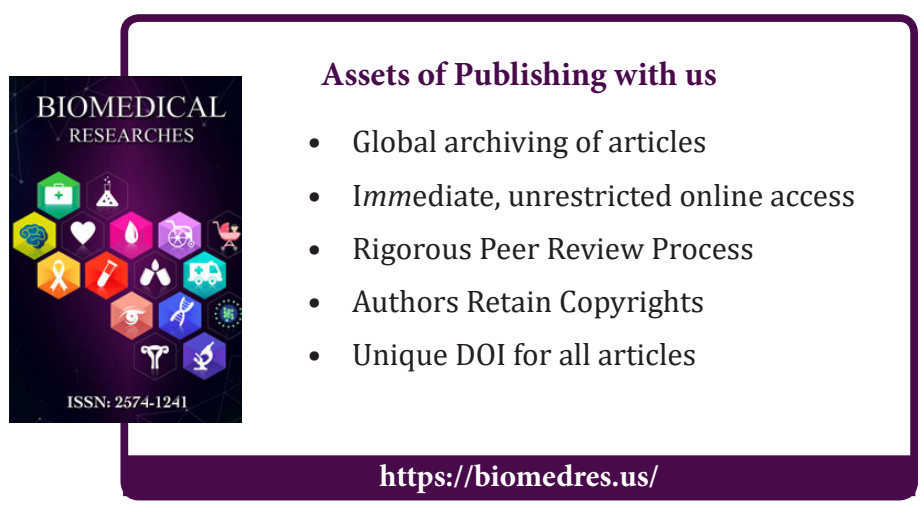

